\title{
DECADENCIA Y MUERTE DEL ESPÍRITU EUROPEO. VOLVIENDO LA MIRADA HACIA OSWALD SPENGLER
}

\author{
Carlos Javier Blanco Martín \\ Universidad de Oviedo
}

\begin{abstract}
Resumen: Oswald Spengler elaboró una concepción pluralista y organicista de la Historia. Según su visión las culturas experimentan una necesidad morfológica, que conlleva nacimiento, esplendor y decadencia antes de la muerte. Occidente está a punto de morir, ya es el cadáver de una Cultura, es decir, una Civilización. El declive militar de los occidentales ante los "nuevos bárbaros", y el sometimiento de lo político a lo económico-financiero marcan nuestra era. Una era unilateral, en la que el "alma faústica" de nuestra cultura discurrió exclusivamente por los canales de la infinitud técnica y de la producción y acumulación insaciable de plusvalía.
\end{abstract}

Palabras clave: decadencia, pluralismo cultural, infinitud unilateral.

\section{Decline and Death of the European Spirit. Returning the gaze towards Oswald Spengler}

\begin{abstract}
Oswald Spengler produced a pluralistic and organicist conception of history. In his view the cultures undergo a morphological necessity, involving birth, splendor and decline before death. West is next to die, it is the corpse of a culture, ie a Civilization. The military decline of the West in front of the "new barbarians" and the subjugation of the political to the economic and financial are marking our age. An unilateral age, in which the "Faustian soul" of our culture is exclusively running on infinity channels and production technique and insatiable accumulation of surplus value
\end{abstract}

Keywords: decline, cultural pluralism, unilateral infinity.

\section{1. ¿Por qué "decadencia"?}

¿Qué significa "decadencia"? Un individuo, una cultura, un pueblo, decaen cuando han traspasado esa línea dorada que un día señaló el esplendor, la plenitud, su "buena forma". El decadente ha conocido tiempos mejores. Aplicada esta noción a las sociedades históricas, saltan a la luz ejemplos diversos que se han convertido en canónicos, y que difunden un inconfundible aroma común.

Decadentes fueron los romanos desde el siglo III d.C. La "pérdida de valores", su degeneración moral, el hecho de confiar en los bárbaros la defensa de sus fronteras, su cristianización incompatible con los valores fundantes de la ciudadanía. Otro tanto podemos decir del Imperio Hispánico: decadentes fueron los españoles, los castellanos, a partir del siglo XVII. Los imperios 
gigantes (Roma, China, España) tardan siglos en morir. Desde una edad dorada, van cayendo por una rampa larga y mortificante, en la que conviven los viejos recuerdos dorados, la pasada gloria, con las más sórdidas realidades del presente inmediato: hambre, depravación, rebajamiento en todos los sentidos de ésta palabra. Sin lugar a dudas lo decadente posee un valor biológico: remite a lo viejo, a cuanto sucede tras una vigorosa madurez. Remite a la pérdida de tono vital, al angostamiento de las energías. Se muestra también con una acepción cercana a la entropía: tendencia al desorden, que en los seres vivos y morales significa "dejar hacer" a la disolución, el aniquilamiento. En sus extremos más deplorables el hombre que abandona la lucha recae en la animalidad bruta, se aliena, esto es, se autoconcibe como cosa. Esta ley termodinámica, y este Principio de Muerte (Tanatos), que consiste en entregarse con placer o desidia a la propia aniquilación moral (depravación, cosificación) o muerte (aniquilación, ascetismo) rige para ciertos individuos o pueblos históricos. La Muerte (meta de la Decadencia) consiste, según el tópico funerario, en un descanso. La Muerte, según saben muchos psicoanalistas, es pariente cercana del Placer y éste, en su paroxismo orgiástico y orgásmico resulta casi indistinguible de Tanatos. Todo lo demás, una vez rebasado el punto más alto de la pendiente, consiste en dejarse llevar. La caída es una forma de vida, y los propios humanos según el relato bíblico de Adán y Eva, somos Pecado, vale decir, caídos. El propio Género, y no ya un individuo o un pueblo, es decadente y ha de verse desnudo, expulsado, dolorido, y avergonzado en suma de su propio existir.

El mejor filósofo de la decadencia es Oswald Spengler. Con su prosa ágil, bella, en ocasiones poética, y con una profundidad y energía propia de los teutones, este autor nos legó una monumental obra: La Decadencia de Occidente.

¿Qué es Decadencia y qué es Occidente? Decadencia es una fase de todo ciclo biológico. Occidente es una Civilización, esto es, el tramo final de una Cultura que ya ha periclitado, que agoniza y muestra su cascarón vacío de formas sin vida. La fosilización de una Cultura se denomina Civilización. Para poder entender el trance en que los occidentales nos encontramos y así poder vislumbrar tendencias hacia el futuro es preciso recurrir a una noción previa en la obra spengleriana: Las Culturas son Organismos.

"Las culturas son organismos. La historia universal es su biografía. La gran historia de la cultura china 0 de la cultura antigua es morfológicamente el correlato exacto de la pequeña historia de un individuo, de un animal, de un árbol o de una flor. Esto, para la visión fáustica, no es una exigencia, sino una experiencia. Sí queremos conocer la forma interna que por doquiera se repite, podemos valernos del método que ha elaborado hace tiempo la morfología comparada de las plantas y los animales [7]. El contenido de toda historia humana se agota en el sino de las culturas particulares, que se suceden unas a otras, que crecen unas junto a otras, que se tocan, se dan sombra y se oprimen unas a otras. Y sí hacemos desfilar ante el espíritu las formas de esas culturas, que hasta ahora han permanecido escondidas bajo el manto de una «historia de la humanidad», concebida como trivial 
sucesión de hechos, conseguiremos sin duda descubrir en su pureza y esencia la protoforma de toda cultura, que, como ideal, sirve de fundamento a todas las culturas Particulars". [LDO, I, 181] ${ }^{1}$

Lejos de entender la Ciencia de la Historia como una sucesión de causas y efectos, un determinismo físico, nuestro filósofo acude a la Biología, a una ciencia natural comparativa e intuitiva, más fundada en Goethe que en Darwin. Para Spengler, la Morfología Comparada es la clase de ciencia que puede orientar al historiador en sus investigaciones. Cada elemento de una morfología cultural puede poseer una pareja (Seitenstück) o correlato que no es accesible a la mirada superficial, aunque sí al ojo experto del comparatista. De la misma manera que el ala del pájaro no recuerda externamente a la garra del cuadrúpedo ni a la mano humana, y sin embargo subyace a todos estos órganos una homología, es decir un sistema de correspondencias. Inspirándose en el Goethe biólogo, Spengler nos insta a buscar la protoforma (Urgestalt) de una Cultura.

Más allá de las apariencias, toda Cultura humana aparece como un sistema orgánico de elementos (arte, política, religión, milicia, mitos...) que guardan correspondencias con elementos de otras culturas. Además, en el seno de ese sistema orgánico, hay un alma troncal desde la que se ramifican dichos elementos y brotan las diversas manifestaciones. En el caso de Occidente, podemos destacar el inmenso contraste entre el Alma Antigua -apolínea, según Spengler- y el Alma Moderna de Occidente -faústica. De forma similar a lo que acontece con una persona, donde hay un cuerpo pero además hay una expresión del mismo que llamamos su alma, también las Culturas conocen esta distinción. Distinción que no es un dualismo, por cuanto que la expresión o manifestación (Ausdruck) habita y reposa en los movimientos y disposiciones del soma. Es por ello que un cuerpo vivo (y una Cultura) no es un cadáver ni una máquina, posee un alma que se expresa somáticamente. Desde la intuición de esa alma, con cuya protoforma podemos barruntar sus posibilidades de realización, brota la comprensión histórico-cultural.

"Distingo por una parte la idea de una cultura, esto es, el conjunto de sus interiores posibilidades, y, por otra parte, la manifestación sensible de

\footnotetext{
${ }^{1}$ A partir de ahora, las citas de La Decadencia de Occidente se harán de la siguiente manera: LDO, I significa tomo primero de la versión castellana de la obra, en la traducción de Manuel G. Morente, Editorial Espasa, Madrid, 2011. Las citas de la versión alemana, DUA, son las iniciales de Der Untergang des Abendlandes, Edición de Beck, Munich, 1923, [Kulturen sind Organismen. Weltgeschichte ist ihre Gesamtbiographie. Die ungeheure Geschichte der chinesischen oder antiken Kultur ist morphologisch das genaue Seitenstück zur Kleingeschichte des einzelnen Menschen, eines Tieres, eines Baumes oder einer Blume. Das ist für den faustischen Blick keine Forderung (exigencia), sondern eine Erfahrung. Will man die überall wiederholte innere Form kennen lernen, so hat die vergleichende Morphologie der Pflanzen und Tiere längst die Methode dazu vorbereitet. Im Schicksal der einzelnen, aufeinander folgenden, nebeneinander aufwachsenden, sich berührenden, überschattenden, erdrückenden Kulturen erschöpft sich der Gehalt aller Menschengeschichte. Und läßt man ihre Gestalten, die bis jetzt nur allzu tief unter der Oberfläche einer trivial fortlaufenden "Geschichte der Menschheit" verborgen waren, im Geiste vorüberziehen, so muß es gelingen, die Urgestalt der Kultur, frei von allem Trübenden und Unbedeutenden aufzufinden, die allen einzelnen Kulturen als Formideal zugrunde liegt.] [DUA, I, 140]
} 
esa cultura en el cuadro de la historia, esto es, su realización cumplida. Es la misma relación que mantiene el alma con el cuerpo vivo, su expresión en el mundo luminoso de nuestros ojos. La historia de una cultura es la realización progresiva de sus posibilidades. El cumplimiento equivale al término. En la misma relación se halla el alma apolínea-que quizá algunos de nosotros puedan sentir y vivir de nuevo-con su desenvolvimiento en la realidad, es decir, con ese conjunto que se llama «Antigüedad», cuyos restos, accesibles a la contemplación y al estudio inteligente investigan el arqueólogo, el filólogo, el estético, el historiador". $[\mathrm{LDO}, 182]^{2}$

En una Cultura hay un cuerpo visible, además de su Idea o alma, y tal cuerpo se nos manifiesta ante la mirada. De la mirada atenta, comparativa e intuitiva del morfólogo surgirá la visión de su alma, un alma visible. Ante nosotros, atentos a la vida de las culturas, están las posibilidades de realización completas de cada una de ellas. Una cultura posee internamente esas posibilidades. Fracaso histórico es el fracaso en no llegar a recorrer esas posibilidades, ese cumplimiento hasta el fin. El cumplimiento es lo mismo que llegar al fin [Die Vollendung ist gleichbedeutend mit dem Ende]. Debería hablarse de una necesidad morfológica, bien distinta de la necesidad en el sentido determinista, darwiniano, mecánico. Spengler repudia el causalismo, ya sea el de tipo eficiente o el teleológico (que es la inversión de aquel). A partir de un protofenómeno (Urphänomen) captado en la Historia Universal, se trata de "estirar" (vollziehen) todas las posibilidades que dimanan de él. Esa Cultura experimenta un nacimiento, un despertar. Desde un fondo oscuro, se despierta un ser a la luz. Las Culturas dormidas están preñadas de posibilidad y deben caminar hacia una luz creciente. Desde la noche, avanzan hacia el Mediodía.

"Una cultura nace cuando un alma grande despierta de su estado primario y se desprende del eterno infantilismo humano; cuando una forma surge de lo informe; cuando algo limitado y efímero emerge de lo ilimitado y perdurable." [LDO, I, 184]

La fase más primitiva de una Cultura es una especie adherencia anímica (urseelenhaften) a ese suelo común y balbuciente sobre el que vive una Humanidad en tinieblas, ignara de sí misma, infantil. La Cultura, al igual que una planta, arraiga en el suelo de una comarca para levantarse sobre él y hacerse grande. Creo que, repasando a fondo estos pasajes de LDO, se me

\footnotetext{
${ }^{2}$ [Ich unterscheide die Idee einer Kultur, den Inbegriff ihrer inneren Möglichkeiten, von ihrer sinnlichen Erscheinung im Bilde der Geschichte als der vollzogenen Verwirklichung. Es ist das Verhältnis der Seele zum lebenden Körper, ihrem Ausdruck inmitten der Lichtwelt unsrer Augen. Die Geschichte einer Kultur ist die fortschreitende Verwirklichung ihres Möglichen. Die Vollendung ist gleichbedeutend mit dem Ende. So verhält sich die apollinische Seele, die einige von uns vielleicht verstehen und miterleben können, zu ihrer Entfaltung in der Wirklichkeit, zur "Antike», deren dem Auge und Verstand zugänglichen Reste der Archäologe, der Philologe, der Ästhetiker und der Historiker untersuchen]. [DUA, I, 141]

${ }^{3}$ [Eine Kultur wird in dem Augenblick geboren, wo eine große Seele aus dem urseelenhaften Zustande ewig-kindlichen Menschentums erwacht, sich ablöst, eine Gestalt aus dem Gestaltlosen, ein Begrenztes und Vergängliches aus dem Grenzenlosen und Verharrenden] [DUA, I, 143].
} 
hace evidente que Spengler tiene en mente una lucha cuando se refiere al nacimiento, esplendor y muerte de las culturas. Pero no es, de manera principal, una lucha darwiniana entre culturas. Desde luego en esa especie de biocenosis que sería la Historia Universal, las culturas coexisten, se funden, se aniquilan, se tocan o se rechazan las unas a las otras. Desde luego hay guerra entre ellas, y una afirmación de cada una contra la que es incompatible. Los ojos de los germánicos a la vista del mármol de las ciudades romanas. La vista de los astures, desde sus montañas cantábricas, a la vista de los llanos islamizados de España. Los ojos de Cortés a la vista de un Imperio Azteca imposible de coexistir en su contacto -si quiera mínimo- con Occidente. Esa mirada del guerrero y del buscador de presas, el animal rapaz que es el hombre, es un hilo que recorre el pensamiento spengleriano de principio a fin. No obstante no me parece el principal. Además de la guerra entre culturas, la caza del hombre por el hombre, la domesticación de otros pueblos o de ciertos estratos del propio pueblo, hay otro género de lucha. La lucha por afirmarse existencialmente: el anhelo por salir de ese suelo indiferenciado. De nuevo, la prosa de nuestro filósofo se nos antoja insuperable:

"Florece entonces sobre el suelo de una comarca, a la cual permanece adherida como una planta. Una cultura muere, cuando ese alma ha realizado la suma de sus posibilidades, en forma de pueblos, lenguas, dogmas, artes, Estados, ciencias, y torna a sumergirse en la espiritualidad primitiva. Pero su existencia vivaz, esa serie de grandes épocas, cuyo riguroso diseño señala el progresivo cumplimiento de su destino, es una lucha intima, profunda, apasionada, por afirmar la idea contra las potencias del caos en lo exterior y contra la inconsciencia interior adonde han ido éstas a refugiarse coléricas". [LDO, I, 184] ${ }^{4}$

Toda cultura sigue un curso, que se nos manifiesta con un trazo (Umriß) único. $Y$ ese perfil dibujado es resultado de una determinada afirmación (Behauptung). La existencia de la Cultura es un sostenerse, un ponerse a la cabeza frente al no ser, frente a lo oscuro e indiferenciado. Las potencias ctónicas, la primacía del seno oscuro y telúrico de la Madre Tierra indiferenciada cede paso a una vida luminosa, a las potencias del empíreo. Igual que Zeus vence a los titanes, la existencia es un nacer en términos de lucha y de victoria. Las potencias oscuras no desaparecen del todo: acaso sea una ley o constante humana el anhelo por regresar al Seno de la Oscuridad y de la Indiferenciación. En ese subsuelo, las potencias vencidas guardan un rencor (grollend) y explican regresos a la barbarie y al salvajismo en toda existencia avanzada, aún más notables en la fase tardía y decadente, en la cual se ha perdido vida, la Idea de Cultura no vivifica y el cascarón vacío de la Civilización da sombra y cobijo a esas regresiones.

\footnotetext{
${ }^{4}$ [Sie erblüht auf dem Boden einer genau abgrenzbaren Landschaft, an die sie pflanzenhaft gebunden bleibt. Eine Kultur stirbt, wenn diese Seele die volle Summe ihrer Möglichkeiten in der Gestalt von Völkern, Sprachen, Glaubenslehren, Künsten, Staaten, Wissenschaften verwirklicht hat und damit wieder ins Urseelentum zurückkehrt. Ihr lebendiges Dasein aber, jene Folge großer Epochen, die in strengem Umriß die fortschreitende Vollendung bezeichnen, ist ein tiefinnerlicher, leidenschaftlicher Kampf um die Behauptung der Idee gegen die Mächte des Chaos nach außen, gegen das Unbewußte nach innen, in das sie sich grollend zurückgezogen haben]. [DUA, I, 143]
} 
La Cultura Occidental ya ha entrado hace tiempo en su fase de decadencia, ya es Civilización. Su alma era el alma fáustica. Un alma que se define por no conocer límites, tender hacia el infinito, crear infinitos. Uno de los aspectos de tal alma viene dado por el poder omnímodo que se ha concedido a lo económico. La historia económico-política de Occidente es la historia de su suicidio como Civilización. Los poderes políticos, las Cartas de Derechos, la más inveterada tradición, todo cuanto fue la Cultura de Occidente es una pura Nada ante el infinito afán acumulativo del Capital, como magistralmente señaló Marx en el contexto del siglo XIX. Muy vinculado a ese aspecto reductor, infinitamente reductor, de la Economía al hacer de todo y de cualquier cosa una Mercancía, viene a colación el papel de la Técnica. Ya vemos signos de cansancio en Occidente en referencia a la Técnica. Oriente le copia, le roba la innovación, y pronto creará la suya propia. Los aprendices de Brujo terminarán con éste que les enseñó y hasta les creó. Una enorme Civilización Técnica, ya no Occidental, se cernirá sobre todo el globo. Al hacer de todas las cosas mercancías y objetos susceptibles de manipulación, Occidente clavó su propio puñal en el pétreo corazón que, aun dentro de la piedra fósil, quizá palpitaba.

Toda Cultura, como organismo viviente, consiste en un tenaz esfuerzo en contra de su entropía. La hipertrofia de sus formas cuando ya su Idea se pierde, cuando ya el principio vital se debilita y experimenta signos de fatiga, deviene en Civilización otoñal. Los caparazones y las formas cadavéricas pretenden conservar la apariencia de una vida que ya agoniza. Ejemplos de ello son las Instituciones fosilizadas, los rituales sin fe, la rutina burocrática, el olvido de las raíces. Así, el mundo occidental se arroga la defensa de unos valores ilustrados (progreso científico, educación universal y permanente, igualdad, bienestar) que ese propio mundo ha ido desmintiendo en sus realizaciones concretas, orientando su alma faústica, su sed de infinitos, únicamente en el sentido acumulativo de plusvalía. No hay límites para la producción de mercancías, para la acumulación de capital, para cosificación del hombre y de la naturaleza.

Pero los viejos valores alcanzados en un mediodía luminoso (llustración, lluminismo), una vez que sirvieron solamente para engrasar una búsqueda fáustica de infinitos mercantiles y tecnológicos, se convierten en valores inválidos, en retórica justificativa de nuevas formas de dominación. Toda la filosofía contemporánea puede comprenderse bajo esta interpretación (Marx, Nietzsche, Weber, Freud, Escuela de Frankfurt, Heidegger). Lo que en una Cultura fuerte y viva es una lucha "artística" contra la propia materia, definida precisamente por su resistencia y oposición (Widerstand), y contra la muerte (Vernichtug) de la Idea, acaba convirtiéndose en un relajo de los esfuerzos y una sumersión de los hombres otoñales de la Civilización en la mera coseidad, en la materia genérica. La obra de arte que es la Cultura viviente se pudre en el fango y se confunde con él.

"Este es el sentido de todas las decadencias en la historia cumplimiento interior y exterior, acabamiento que inevitablemente sobreviene a toda cultura viva-. La de más limpios contornos se halla ante nuestros ojos; es la «decadencia de la antigüedad». Y ya hoy podemos rastrear claramente en nosotros y en torno a nosotros los 
primeros síntomas de la decadencia propia, de la «decadencia de Occidente», acontecimiento que por su transcurso y duración coincide plenamente con la decadencia de la antigüedad y se sitúa en los primeros siglos del próximo milenio" [LDO, I, 184-185 $]^{5}$

El paralelismo es muy grande. Grecia asimilada al gran imperio de Roma. Pero Roma ya periclitada en sus viejos valores republicanos, Imperio desmesurado infiltrado de barbarie en sus ciudades, su ejército, en su espíritu. Roma como esqueleto y despojo listos para el botín de pueblos muy inferiores en desarrollo cultural, pero más vigorosos. El alma vieja se convierte en alfombra para el paso de las almas más jóvenes que aprovechan su oportunidad para entrar en el escenario de la Historia, para salir de la oscura existencia puramente animal y étnica. Vayamos al hoy: la vieja Europa de las "potencias", el club de naciones colonialistas que hace poco más de un siglo creían repartirse el mundo, es la Grecia cada vez más provinciana (provincia: vencida), la "aliada" de unos Estados Unidos con vocación imperial, pero gravemente aquejada de cansancio. La versión bárbara de una Europa clásica que ya nadie recuerda, de una llustración y una filosofía liberal defendida fuera de contexto, en el contexto de la producción infinita de mercancías y de la mercantilización infinita del género humano y la naturaleza. La "barbarie" en el sentido estricto de extranjería va a vencer. Los E.E. U.U. no han vencido una sola guerra en tiempo y forma desde 1945, fecha en que sucumbió Europa como proyecto imperial. Se derrotó a Hitler y al Imperio Japonés, pero ahí están los humillantes recuerdos de Vietnam, Irak, Afganistán.

De forma correspondiente los occidentales ya hemos pasado por nuestro manierismo helenístico, y estamos a punto de ver sucumbir un mundo que ya no podemos comprender bajo los moldes clásicos en que algunos (acaso una minoría de entre los universitarios) habíamos interiorizado.

El hábito (Habitus) de esta Civilización se desdibuja. Los que somos hijos de Occidente ya no podemos vislumbrarlo. Spengler postula una ciencia fisiognómica (tomada de Goethe) en la que puedan reconocerse los elementos interiores y exteriores de una Cultura como especie contradistinta de las demás. El naturalista busca en los rasgos exteriores de una planta su peculiar carácter, rasgos de su fisionomía que abren la puerta a un conocimiento de su alma. En la ciencia de la Historia, estos rasgos son el alma expresada. Por ejemplo, una Catedral gótica no se alza en medio de un desierto arábigo o norteafricano, de la misma manera que no llegaron a alzarse mezquitas en Cangas de Onís u Oviedo. Viena no llegó a quedar bajo el imperio de la media luna. Las ciudades administrativas creadas por los blancos al sur del Sahara no irradiaron burocracia y democracia fuera de sus arrabales, donde la negritud sigue viviendo en sus poblados y formas tribales. Solamente la nueva forma de barbarie generalizada, es decir, la universalización de la condición de

\footnotetext{
${ }^{5}$ [Dies ist der Sinn aller Untergänge in der Geschichte - der inneren und äußeren Vollendung, des Fertigseins, das jeder lebendigen Kultur bevorsteht -, von denen der in seinen Umrissen deutlichste als "Untergang der Antike " vor uns steht, während wir die frühesten Anzeichen des eignen, eines nach Verlauf und Dauer jenem völlig gleichartigen Ereignisses, das den ersten Jahrhunderten des nächsten Jahrtausends angehört, den "Untergang des Abendlandes", heute schon deutlich in und um uns spüren].[DUA, I, 144]
} 
extranjero que se difunde desde las grandes urbes "cosmopolitas" está dando pie a ese hombre-cosa que no posee patria, y que encuentra todas las culturas (aunque en forma impostada, descontextualizada y alienada) en la superficie asfaltada de unos pocos kilómetros cuadrados de una población mal llamada ciudad, pues allí no se acumulan ciudadanos. Todos somos extranjeros en la festejada y bendecida aldea global. ¿Era, es, el sino de Occidente un hundirse en el cieno, la entropía, la aldea global? El historiador-filósofo debe escudriñar las tendencias que desde hace siglos apuntan en Europa hacia esa decadencia. Por debajo de una unión monetaria y de una superestructura burocrática uniformizada, las formas superiores de Cultura (Arte, Religión) mueren, pues muere la Civilización que todavía las acoge. La novena sinfonía de Beethoven suena hueca como himno de un formalismo, todavía no como himno de una verdadera federación. Las catedrales góticas se alzan sin que los descendientes de aquellos constructores acierten a entender ya esa verticalidad, esa oposición fundamental al alma cueviforme (representada ya por la cúpula romana tardía, la bizantina y finalmente la mezquita arábiga). El sino, y la noción certera del mismo [Gewißheit eines Schicksals] se intuyen a través de estas manifestaciones, antes que por los conceptos y la ciencia.

"El que comprenda bien el sentido en que se puede decir que el alma es la idea de una existencia, comprenderá asimismo que en el alma ha de residir la certidumbre de un sino] y que la vida misma-que he llamado la forma de realizarse la posibilidad-debemos sentirla como orientada en una dirección, como irrevocable y regida por un sino. Este sentimiento del sino despunta confuso y angustioso en el hombre primitivo; luego ya aparece claro y reducido a la fórmula de una concepción del mundo, en el hombre de las culturas superiores, aun cuando sólo es comunicable por medio del arte y de la religión y nunca por demostraciones y conceptos". [LDO, I, 193] $]^{6}$

La Ciencia de la Historia, en tanto que es el escrutinio del Tiempo y de sus líneas posibles, se constituye en fundamento de toda otra ciencia exclusivamente fundada en el Espacio, ciencia causalista en la que las ordenaciones -ya sean del tipo causa-efecto o del tipo medios-fines- es ciencia que niega el Tiempo, lo excluye y sólo cuenta como secuencia de operaciones del Sujeto, como orden de hechos o acontecimientos. Ni Goethe ni Spengler entendieron así una verdadera Ciencia de lo Temporal: no se puede hacer Historia mediante conceptos causales o mecánicos. Por el contrario, antes que vernos con una ciencia de conceptos en los que el Tiempo es escamoteado y pensado como un cuasi-espacio, nos encontramos con una especie de intuicón del Porvenir, del Destino (Schicksal). La historia morfológica comparada de las Culturas y Civilizaciones habla por sí misma de la muerte de la nuestra, la Occidental si prosiguen estas tendencias, si no hubiera en los siglos venideros

\footnotetext{
${ }^{6}$ [Wer überhaupt versteht, inwiefern man die Seele als Idee eines Daseins bezeichnen kann, der wird auch ahnen, wie nahe verwandt ihr die Gewißheit eines Schicksals ist und inwiefern das Leben selbst, das ich die Gestalt nannte, in welcher die Verwirklichung des Möglichen sich vollzieht, als gerichtet, als unwiderruflich in jedem Zuge, als schicksalhaft hingenommen werden muß - dumpf und ängstigend vom Urmenschen, klar und in der Fassung einer Weltanschauung, die allerdings nur durch die Mittel der Religion und Kunst, nicht durch Begriffe und Beweise mitgeteilt werden kann, vom Menschen hoher Kulturen].[DUA, I, 153]
} 
unas mutaciones que, en realidad, anunciarán nuevas formas de Cultura. El alma gótica (faústica) habitaba ya en aquellos bárbaros germánicos que oteaban por encima del limes de Roma, que penetraban en él, ora con permiso ora sin él. De Pericles a Nerón se había recorrido un tiempo, una línea de siglos con sentido -sino- irreversible. Que es eso lo que significa historia y tiempo: irreversibilidad. Que las Culturas sean organismos vivos y por ende cíclicos, no obsta para que el fin de un ciclo sea al punto nacimiento, sí, pero nacimiento de un ser completamente nuevo. Por ello San Agustín, vestido y educado como un romano tardío del siglo $\mathrm{V}$ es un fin de ese Imperio al que ya en realidad denigra y condena, y su alma parece "arábiga" en el sentido spengleriano. Por ello el cristianismo primitivo, el de las catacumbas y primeras predicaciones en el Imperio de Roma y el Oriente no muestra continuidades con el cristianismo gótico (faústico) de las Cruzadas y de las Catedrales.

Para ser capaces de ver una "lucha entre civilizaciones" en la compleja biocenosis de la Historia no podemos servirnos de abstracciones que sobrevuelen el recorrido de cada alma colectiva. No hay, por tanto, una lucha abstracta entre Cristiandad e Islam. Las campañas de Alfonso III de Asturias, Covadonga o las Navas de Tolosa, las Cruzadas, Lepanto... no son conmensurables con las guerras de Mr. Bush, la caza y muerte de Bin Laden, los atentados del 11-S en los EEUU...La "Religión" no siempre dividió a los pueblos, las razas, las naciones. La "Religión" no siempre fue un vector de organización bélica con el que poder alzarse frente a otro vector opuesto, igualmente de naturaleza religiosa. Qué entendamos por "Religión" es cosa muy variable en las épocas, en las latitudes. El germano y el celta se cristianizaron conservando fondos insondables de sus razas, que bien pudieron hacer mutar esa religión venida del Levante. El afroamericano caribeño reza a los santos católicos y practica el animismo de sus ancestros. Hay sincretismos y hay mutaciones. La "Religión" es poca cosa al margen de los pueblos que la defienden, que creen en sus dogmas, que la practican. Acierta Spengler en verla, como el Arte, como vehículo expresivo de una Cultura, mas la Cultura es la verdadera planta, el ser que hunde su raíz en la tierra y en la vida. Alfonso III de Asturias creía ser un nuevo rey godo, cuando lo cierto es que la mayoría de los godos de verdad estaban islamizados o bajo tutela de los francos. La "lucha entre civilizaciones" no es la idea clave en La Decadencia de Occidente, aunque pueda parecerlo. Más bien es el curso orgánico de desarrollo de cada Cultura, que desemboca en Civilización (un Nacimiento y Muerte) lo que nos depara la ciencia de la Historia. Occidente no precisa de talibanes o de otro género de bárbaros: Occidente caerá solo. Ese es el sino si no hay entre nosotros una mutación.

Las estructuras más primitivas, que Carl G. Jung llamaría arquetipos, no desaparecen en el proceso de formación y desarrollo cultural. Antes bien, hay un despliegue de esos modelos impresos en el alma. En el capullo de una amapola hace falta emplear la fuerza violenta de los dedos para ver que unos pequeños pétalos rojos se esconden todavía en el estuche verde de una flor que todavía esconde (con necesidad morfológica, como dice Spengler) sus rasgos de identidad más característicos. Algo parecido cabe decir de pueblos todavía primitivos a punto de conocer una "mutación", así como de las Altas Culturas que, en un determinado trance de su declinar anuncian una Era 
totalmente nueva. Los Arquetipos que yacían dormidos, despojados de adherencias recientes, emergen de nuevo y prevalecen sobre otros que pasan al olvido.

Occidente, y de manera eminente Europa, es hoy un amasijo de arquetipos dormidos y olvidados. La verticalidad de las catedrales góticas, la jerarquía de noblezas guerreras y de estamentos caballerescos, el espíritu de Cruzada o el amor cortés... Todo parece que yace sepultado. Lo sepultaron las trincheras y las fosas comunes de las guerras mundiales así como el pavimento de las innumerables calles de las grandes urbes. Allí, como dice nuestro filósofo, se ha criado una clase de hombre excesivamente vigilante para con los conceptos que mecánicamente debe emplear en su vida cotidiana de asalariado, técnico, comerciante, burócrata. Es un "gestor" -como se dice tan a menudo ahora- de conocimientos, no un creador ni alguien lo suficientemente intuitivo ni místico como para poder encontrar otros anhelos (faústicos) más allá de la ganancia ilimitada, el enriquecimiento ilimitado, el bienestar ilimitado. ¡Qué anhelos más contradictorios todos ellos! Esa unilateralidad del alma faústica que se ha permitido el lujo de circunscribirse a la Economía Política y a la Técnica será, escrutando el sino, la clave de su futuro suicidio y de su segura esclavitud. Los Estados nacionales sometidos a los dictados de opacos mercados financieros, la supuesta cuna de la libertad individual, de los derechos fundamentales, de la democracia, la filosofía, la igualdad de género... Esa cuna está ahora habitada por millones de mansos habitantes de grandes ciudades, muchos de ellos ancianos y otros muchos son mano de obra inutilizable por tratarse de una mercancía demasiado cara. Los arquetipos colectivos del guerrero, del aventurero, del noble rapaz, del generoso dador pero cruel dominante (todos ellos, muy del gusto Nietzscheano) en la medida en que reposan en el fondo del alma europea ¿qué fue de ellos? ¿A dónde se fueron después de Auschwitz, después de la derrota de un Imperio Germánico? La monstruosidad nazi vino preparada por el industrialismo y la visión totalitaria del Estado como Dios en la Tierra. Y, a su vez, la Técnica -como dominación de la naturalezamás el Estado -como dominación sobre los hombres, se asentaron en un restringido concepto de Mundo, entendido como cadena causal. Domina quien pone su mano en la cadena y es capaz de tirar de ella, y así oprimir al que está al otro lado.

\section{La Fisiognómica}

La visión fisiognómica de Spengler guarda estrecha relación con un conocimiento de lo naciente, no de lo nacido.

"El que conciba el mundo sensible de manera sistemática y no físiognómica; el que se lo apropie por medio de experiencias causales creerá necesariamente que comprende toda vida desde el punto de vista de la causa y el efecto, esto es, sin dirección interna, sinmisterio. Pero el que, como Goethe y como casi todos los hombres, en casi todos los momentos de su existencia (existencia despierta: seines wachen Daseins), deja que el mundo circundante impresione sus sentidos y se asimila la totalidad de esa impresión; el que siente lo producido como un 
producirse y arranca al universo la rígida máscara de la causalidad; el que no retuerce su mente en reflexiones lógicas, ese comprende al punto el enigma del tiempo; para él el tiempo ya noes ni un concepto, ni una «forma», ni una dimensión, sino algo que se siente en la intimidad personal con profunda certidumbre para él el tiempo es el mismo sino; y su dirección, su irreversibilidad, su vitalidad, le aparecen ahora como el sentido del universo en su aspecto histórico". [LDO, I, 195]

El mundo como producirse [das Gewordne als werdend fühlt] y el mundo como producido. Historia frente a Ciencia Natural. Esta es una oposición también presente en Spengler, pero muy distinta a otros historicismos. En este caso hay una intuición del proceso vital de las Culturas, de lo viviente, que es la precondición de los hechos de la propia ciencia natural. El tiempo, su sino, su irreversible índole, arraiga en el interior del Sujeto [una certeza interna: sondern etwas innerlich Gewisses]; Occidente lleva siglos enmascarado bajo la categoría de causa, categoría que la Fisiognómica de la Historia puede "ventilar" (lüften). La categoría de causa y su condición necesaria, el espacio (que incluye un tiempo espacializado) es, en realidad, un logro tardío. La historia de la concepción legalista del cosmos (causa y ley, es lo mismo) es breve (25 siglos) y geográficamente reducida. Solo cuando una Alta Cultura, como la griega, llega a un alto grado de florecimiento y gira en torno a la ciudad, donde el pensamiento se abstrae del agro, de las manos encallecidas, del riesgo de morir cazado por las fieras o por los enemigos, solo en ese espacio callejero, ordenado y civilizado, algunas mentes llegan a pensar en términos causalistas y meramente espaciales. Entonces triunfa la lógica y se sepulta la intuición. El famoso "paso del Mito al Logos" fue -en puridad- la lucha entre el Mito y el Logos. La lucha ganada por el concepto y el número (en el fondo, es lo mismo) frente a la intuición.

Sin embargo es esa facultad intuitiva, la visión inmediata de los aconteceres no la ordenación y clasificación de los hechos, la única que nos permite cultivar la Historia en el sentido grande de la palabra. La estadística, la cronología, el pensamiento causalista del materialismo histórico, etc. pueden ser útiles para una ciencia propedéutica de la Historia, mas no la Historia misma. La visión intuitiva de la Historia vislumbra el sino de los aconteceres, explora esa masa oscura de posibilidades que llamamos Futuro, y se sumerge en otra masa no menos oscura y colvulsa: la masa del Pasado. Por ello el verdadero amante de la Historia, el filósofo de la Historia, se acerca, según Spengler, mucho más al poeta, al creador, que al físico. Cuando la intuición histórica re-crea una época, una cultura, el ciclo de vida de los pueblos, su acto es acto creador. El físico

\footnotetext{
${ }^{7}$ [Wer die Lichtwelt seiner Augen nicht physiognomisch, sondern systematisch erfaßt, sie durch das Mittel kausaler Erfahrungen sich geistig aneignet, wird zuletzt mit Notwendigkeit alles Lebendige aus der Perspektive von Ursache und Wirkung zu verstehen glauben, ohne Geheimnis, ohne inneres Gerichtetsein. Wer aber wie Goethe, wie jeder Mensch in weitaus den meisten Augenblicken seines wachen Daseins, die Umwelt nur auf seine Sinne eindringen läßt und die Gesamtheit dieses Eindrucks hinnimmt, das Gewordne als werdend fühlt, die starre Weltmaske der Kausalität lüftet indem er einmal nicht nach-denkt, für den ist die Zeit plötzlich kein Rätsel mehr, kein Begriff, keine „Form «, keine Dimension, sondern etwas innerlich Gewisses, das Schicksal selbst; ihr Gerichtetsein, ihre Nichtumkehrbarkeit, ihre Lebendigkeit erscheint als der Sinn des historischen Weltaspekts. Schicksal und Kausalität verhalten sich wie Zeit und Raum.] [DUA, I, 154]
} 
disecciona, aniquila, mata cuanto se tienda ante su mesa de trabajo, presto a una descomposición metódica. Un pasado de hechos es un pasado muerto, y por ello, sobre el cadáver, resulta relativamente sencillo emprender mediciones, controlar factores causales, establecer estadísticas, cronologías, secuencias explicativas. Pero el creador en la Historia busca el alma de los pueblos, de las culturas: rastrea los gestos vivientes de esas entidades: es la ciencia fisiognómica que Spengler opone a la sistemática. Un materialista histórico, igual que un positivista, tratará de ofrecer un cuadro de la "Humanidad" dividida según modos de producción, alcances tecnológicos, sistema de clases sociales, etc. La presencia o ausencia de determinados factores explicativos es la guía para la construcción de esas tablas. Pero el alma de las distintas culturas sigue sin tocarse por tales operaciones.

Spengler describe, con prosa insuperable, el espectáculo que se abre a la intuición
"Una masa inabarcable de seres humanos, un torrente sin orillas, que nace en el pasado sombrío, allá donde nuestro sentimiento del tiempo pierde su eficacia ordenativa y la fantasía inquieta-o el terror-evoca la imagen de los períodos geológicos, para ocultar tras ella un enigma indescifrable; un torrente que va a perderse en un futuro tan negro e intemporal como el pasado; tal es el fondo Sobre que se destaca la imagen fáustica de la historia humana. El oleaje uniforme de las innumerables generaciones estremece la amplia superficie. Refulgentes destellos surcan los ámbitos. Inciertas luces se agitan temblorosas, enturbiando el claro espejo; se confunden, brillan y desaparecen. Las hemos llamado razas, pueblos, tribus. Reúnen una serie de generaciones en un limitado circulo de la superficie histórica, y cuando se extingue en ellas la fuerza creadora-fuerza muy variable, que prefija a esos fenómenos una duración y plasticidad también muy variables- extínguense asimismo los caracteres fisiognómicos, lingüísticos, espirituales, y la Concreción histórica vuelve a disolverse en el caos de las generaciones. Arios, mongoles, germanos, celtas, partos, francos, cartagineses, bereberes, bantúes, son nombres que aplicamos a muy distintas formaciones de este orden. Sobre esta superficie describen las grandes culturas sus círculos majestuosos. Emergen de pronto, extienden a lo lejos sus magnificas curvas, debilítanse luego y desaparecen. Y el espejo del agua sigue terso, solitario, adormecido" [LDO,I, 183] $]^{8}$

\footnotetext{
${ }^{8}$ [Eine unübersehbare Masse menschlicher Wesen, ein uferloser Strom, der aus dunkler Vergangenheit hervortritt, dort, wo unser Zeitgefühl seine ordnende Wirksamkeit verliert und die ruhelose Phantasie - oder Angst - in uns das Bild geologischer Erdperioden hingezaubert hat, um ein nie zu lösendes Rätsel dahinter zu verbergen; ein Strom, der sich in eine ebenso dunkle und zeitlose Zukunft verliert: das ist der Untergrund des faustischen Bildes der Menschengeschichte. Der einförmige Wellenschlag zahlloser Generationen bewegt die weite Fläche. Glitzernde Streifen breiten sich aus. Flüchtige Lichter ziehen und tanzen darüber hin, verwirren und trüben den klaren Spiegel, verwandeln sich, blitzen auf und verschwinden. Wir haben sie Geschlechter, Stämme, Völker, Rassen genannt. Sie fassen eine Reihe von Generationen in einem beschränkten Kreise der historischen Oberfläche zusammen. Wenn die gestaltende Kraft in ihnen erlischt - und diese Kraft ist eine sehr verschiedene und bestimmt von vornherein eine sehr verschiedene Dauer und Plastizität dieser Bildungen -, erlöschen
} 
La descripción del nacimiento -o despertar- de un alma, del alma faústica, que Oswald Spengler lleva a cabo es plástica en grado sumo. Hay siempre un fondo o subsuelo (Untergrund); hay un movimiento caótico en los dos sentidos de nuestra mirada intuitiva, el pasado (Vergangenheit) y el futuro (Zukunft). La emergencia (auftauchen) de una tal alma faústica a partir de un raudal de pueblos, razas, naciones, aconteceres, es retratada por nuestro filósofo de la misma manera en que la obra de arte sale de la paleta y pincel del pintor, o de la forja o el cincel del creador en escultura. La historia es movimiento creador, y su intuición es también la artística visión de formas que aparecen en medio de las aguas caóticas. Por ello las palabras "plástico", "forma", "trazo", "perfil", o sus equivalentes en lengua alemana, son términos que transitan con frecuencia en La Decadencia de Occidente.

Quizá se comprenda ahora mejor por qué la Morfología de tipo fisiognómico de Spengler no supone exactamente una teoría de la "lucha de civilizaciones". Esta, cuando la hay, no constituye el proceso fundamental de la emergencia de las culturas, o de su supervivencia en la biocenosis donde otras especies culturales florecen y buscan su propio destino. Es precisamente este florecer endógeno de las culturas de los grandes pueblos (repárese en la lista de ejemplos que hemos acotado arriba: Arios, mongoles, germanos, celtas, partos, francos, cartagineses, bereberes, bantúes...) lo que da a la historia de la "Humanidad" su evidente tono pluralista. Cada cultura sigue los pasos de su sino, recorre las posibilidades de su propia endogénesis. Entre esas posibilidades se encuentran desde luego, estas: el exterminio recíproco, la fusión étnica o la esclavitud, el colonialismo, la guerra de rapiña, etc. Pero dichas posibilidades y acontecimientos no pueden entenderse como motores de la explicación histórica. La necesidad morfológica llevó a Roma a su cristianización, a su decadencia, a "dejarse invadir". La necesidad morfológica llevó al Imperio Hispánico a romperse en territorios pobres y famélicos. Siempre hay hostigadores, enemigos, competidores. Pero no se puede confundir la obra spengleriana con un darwinismo social de Civilizaciones en confrontación, ni con un Estado de Naturaleza hobbesiano.

Antes bien, vemos en Spengler una decidida defensa del pluralismo cultural, y un pesimismo evidente a la hora de postular cualquier "diálogo de las civilizaciones". Cada Cultura es especie única en su género y sus mixturas con otras apenas pueden llegar a ser parciales, limitadas en su ámbito. San Agustín era maestro de retórica, conocedor de la tradición latina, pero "arábigo" en su alma. Su universo mental era la cueva del "sometido" (como indica la palabra islam, o la obra La Ciudad de Dios) al poder omnímodo de Dios. Los reyes y nobles godos de Toledo habían sido siglos atrás errabundos y fieros guerreros germánicos, pero instalados en su reino hispano vestían y vivían como sátrapas orientales, o imitando el lujo de los emperadores bizantinos. Los

auch die physiognomischen, sprachlichen, geistigen Merkmale, und die Erscheinung löst sich wieder in dem Chaos der Generationen auf. Arier, Mongolen, Germanen, Kelten, Parther, Franken, Karthager, Berber, Bantu sind Namen für höchst verschiedenartige Gebilde dieser Ordnung. Über diese Fläche hin aber ziehen die großen Kulturen ihre majestätischen Wellenkreise. Sie tauchen plötzlich auf, verbreiten sich in prachtvollen Linien, glätten sich, verschwinden, und der Spiegel der Flut liegt wieder einsam und schlafend da.] [DUA,I, 142] 
ropajes cambiados pueden expresar -o no- un cambio plástico del alma. Las culturas declinantes, a punto de petrificarse en forma de civilizaciones, adoptan ya los cambios estéticos necesarios para arrojar la toalla de los vencidos. El gentleman de la city londinense o de cualquier otra capital europea no tiene nada que hacer con su elegante traje y corbata salvo en el limitado mundo de los negocios. Las calles pertenecen ya a la legión "afro", como salida de un barrio neoyorquino, vestida con sus holgadas prendas del rap, el hip-hop, la "cultura" del graffiti, o cualquier otra submanifestación (underground) elevada ya al rango oficial. La estética marca los límites más plásticos al historiador intuitivo. Un mundo clásico que declina, otra época nueva que llega. Una Civilización "que ya ha dado todo de sí" frente a un magma nuevo que irrumpe. La intuición histórica es también fundamental para la comprensión del presente, pues los ciclos de las culturas, su nacimiento y muerte, ya se han dado muchas otras veces. Nuestra civilización- que agoniza- no es la única, ni tampoco será "la mejor" ni la "definitiva". Alejado se encuentra Spengler de toda tentación etnocentrista: isu obra fundamental es un ataque directo a las ilusiones etnocentristas! De ahí que su mala prensa entre la izquierda multiculturalista, las acusaciones más o menos veladas de su afinidad con el nazismo, etc. se muestren como ridículas a todas luces. Son acusaciones que se explican únicamente por un profundo desconocimiento de lo que este filósofo malentendido y marginado pese a ser muy leído- nos dejó escrito.

\section{Concluyendo: Pluralismo versus multiculturalismo.}

Es Spengler un pluralista cultural. Lejos de él está el abstracto universalismo: el de Kant, Hegel, Marx...el de toda la Economía moderna, el de la "religión" de los derechos humanos y de la "democracia para todos". No todas las culturas pueden discurrir por los mismos raíles, cada una posee su ritmo, su tiempo, su trazado característico. La verdadera faz del universalismo, a tenor de cuanto defiende Spengler, es verdaderamente el etnocentrismo, prejuicio del que nuestro autor está curado. Insertar un conocimiento y respeto jacobinos a la Declaración Universal de los Derechos Humanos, lejos del suelo francés, en tierras donde mandan el burka y las lapidaciones, es ingenuidad etnocéntrica. Creer que una implantación universal de la Educación para la Ciudadanía conseguirá una humanidad multicultural pero impregnada de "valores universales" vale decir, comunes, es un idealismo infantil, un torpe hálito infantil, inusitadamente salido del cadáver "Europa" que una vez caminó por el mundo con paso propio y que se engolfó por las sendas de la llustración. Nada de estas ingenuidades ilustradas podemos ver en La Decadencia.

El Problema de la llustración y su "Dialéctica" (Adorno y Horkheimer) consistió precisamente en pretender organizar un mundo -una época, una Civilización que ya otoñaba- como si se tratara de un sistema lógico, un cómputo de conceptos. Su "saber para prever" hizo del mundo una Lógica. Comte o Hegel, cada uno a su manera, llevaron adelante su monstruosa teoría, esto es, la degeneración de la exhortación ilustrada del Sapere aude en pura voluntad de poder (única degeneración posible en un modo de producción que iba en camino de ser industrial, por lo demás). Positivismo, marxismo, utilitarismo, en el fondo derivaron de esta cenital evolución del ideal ilustrado. Unas 
abstracciones carentes de vida quedaron disponibles, bajo los pomposos rótulos de "ciencia" y "conocimiento", con el fin exclusivo de asentar sobre ellas una red de procedimientos técnicos. El propio pensamiento devino en técnica de conceptos y, por lo tanto, en simple técnica. La técnica y la sistemática de conceptos operan con lo ya muerto. No es posible la Historia como ciencia. La Historia es el saber del producirse, no de lo producido como han pretendido las otras corrientes de filosofía historicista del XIX.

"En las dos posibles imágenes del mundo, en la historia y en la naturaleza, en la fisonomía de todo el producirse y en el sistema de todo lo producido, imperan, pues, el sino o la causalidad. Existe entre ellos la misma diferencia que entre el sentimiento vital y el conocimiento. Cada uno es el punto de partida de un mundo perfecto, concluso, pero que no es el único posible. Mas el producirse es el fundamento de lo producido, y consiguientemente la intima y segura sensación de un sino sirve de base al conocimiento de las causas y los efectos. La causalidad es-si se me permite la expresión-el sino realizado, transformado en cosa inorgánica, petrificado en las formas del entendimiento, El sino-junto al cual han pasado silenciosos todos los constructores de sistemas intelectualistas, como Kant, porque les era imposible captar lo viviente con sus abstracciones privadas de vida-el sino reside más allá y fuera de toda concepción naturalista. Pero siendo lo primario es él quien da al principio de causalidad, principio muerto y rígido, la posibilidadhistórico-vital- de aparecer como la forma y complexión de un pensamiento tiránico, en las culturas muy desarrolladas. La existencia del alma antigua es la condición sin la cual no se hubiera producido el método de Demócrito; la existencia del alma fáustica es la condición del de Newton". [LDO, I, 195] ${ }^{9}$

He aquí la gran diferencia: el producirse que forma una fisonomía de todo lo que nace o brota $y$ el sistema de lo nacido [der Physiognomie alles Werdens und dem System alles Gewordenen]. Es un gran escalón, un desnivel profundo el que media entre causa y sino. La causa es, por así decir, el sino congelado (erstarrtes Schicksal). El sino es lo primario y espontáneo (Ursprüngliche)], por ello cabe atribuir intuición del sino incluso en los hombres más arcaicos, presos de un primitivismo que nos parece lejanísmo a nosotros. Pero sobre la base de

\footnotetext{
${ }^{9}$ [In beiden möglichen Weltbildungen, in Geschichte und Natur, der Physiognomie alles Werdens und dem System alles Gewordenen, herrschen also Schicksal oder Kausalität. Zwischen ihnen besteht der Unterschied eines Lebensgefühls und einer Erkenntnisweise. Jedes von ihnen ist der Ausgangspunkt einer vollkommenen und in sich geschlossenen, nur nicht der einzigen Welt. Aber das Werden liegt dem Gewordenen, das innere und gewisse Fühlen eines Schicksals mithin dem Erkennen von Ursache und Wirkung zugrunde. Kausalität ist - wenn man sich so ausdrücken darf - gewordenes, entorganisiertes, in Formen des Verstandes erstarrtes Schicksal. Das Schicksal selbst, an dem alle Erbauer verstandesmäßiger Weltsysteme wie Kant schweigend vorübergegangen sind, weil sie das Leben mit ihren vom Leben abgezogenen Grundbegriffen nicht zu berühren vermochten, steht jenseits und außerhalb aller begriffenen Natur. Als das Ursprüngliche aber gibt es dem toten und starren Prinzip von Ursache und Wirkung erst die - geschichtlichlebendige Möglichkeit, innerhalb hochentwickelter Kulturen als Form und Verfassung eines tyrannischen Denkens aufzutreten. Das Dasein der antiken Seele ist die Bedingung für die Entstehung der Methode Demokrits und das der faustischen für diejenige Newtons]. [DUA,I, 155]
} 
ese primitivismo y de su conciencia del sino, como condición (Bedingung) pudieron desarrollarse sistemas que damos en llamar "científicos".

No se trata aquí de una crítica de la ciencia, muy al uso en nuestros días: ciencia como manipulación, como técnica de sometimiento, control y dominación de los seres humanos y de los demás seres naturales, etc. Se trata más bien de una inserción de la ciencia en el curso de la Cultura Occidental como producto tardío, esencialmente conceptual y, por ende, congelado y muerto, asentado en el principio de causalidad. Este principio aparece en contextos ya urbanos, otoñales, distantes del magma mítico y de las intuiciones de lo naciente. No es una crítica a la ciencia como las que se hacen hoy en día de la mano de Nietzsche, Marx, la escuela de Frankfurt, etc., en general consistentes en salirse de sus círculos categoriales sacando solo uno de los pies, contentándose con atravesarlos con leves agujas críticas ("de segundo grado", según la célebre definición de la Filosofía como mero saber crítico). No, aquí tenemos una propuesta mucho más grande, un desafío: Spengler propone hacer de la Historia un saber superior. Su fisiognómica es, en el más ambicioso de los sentidos, el fundamento sobre el que reposa la ciencia causalista. Todo el castillo de naipes de las causas y los efectos reposa en el sino, en la aprehensión del sino. La tradición racionalista no ha podido verlo. Desde Sócrates, la filosofía ha devenido una técnica de conceptos. Spengler habla de Aristóteles y de Kant como autores que, en el fondo, eran lógicos, no practicantes de la ciencia suprema. Y la lógica, como el causalismo, constituye la negación del tiempo, la ahistoricidad máxima.

Quizá existan lectores que vean en La Decadencia de Occidente una vía al relativismo. Al quedar la ciencia y el pensamiento lógico-causal tan ceñido a las civilizaciones maduras, a punto de resultar seniles y por ende, civilizaciones rígidas en sus formas, llenas de conceptos muertos, quizá se pretenda sostener que no hay verdades salvo las utilitarias para el modo de producción y reproducción de estas Civilizaciones. Que no hay verdad en sí. Antes bien, yo estimo que el mensaje valioso de la obra spengleriana reside en su pluralismo ontológico: la incomprensión recíproca entre las culturas, el hecho de que veamos el cuadro de la Historia Universal como un jardín abigarrado, formado por plantas y floraciones diversas, nos permite destacar el cariz inacabado y nunca teleológico de nuestra especie, la importancia de la diversidad étnica, lingüística, cosmovisional de los hombres, el rechazo no romántico sino necesario que puede y debe provocar toda gobalización. 